\title{
Voltage Distortion Mitigation in a Distributed Generation- integrated Weak Utility Network Via a Self-tuning Filter-based Dynamic Voltage Restorer
}

\author{
Samet Biricik \\ European University of Lefke (Cyprus), samet@biricikelektrik.com \\ Shafiuzzaman Khadem \\ Tyndall National Institute, Cork \\ Soydan Redif \\ European University of Lefke (Cyprus)
}

See next page for additional authors

Follow this and additional works at: https://arrow.tudublin.ie/engscheleart2

Part of the Electrical and Computer Engineering Commons

\section{Recommended Citation}

Biricik, S., Khadem, S., Redif, S. \& Basu, M. (2018). Voltage distortion mitigation in a distributed generation-integrated weak utility network via a self-tuning filter-based dynamic voltage restorer. Electrical Engineering, 100, pp.1857-87. doi:10.1007/s00202-017-0666-4

This Article is brought to you for free and open access by the School of Electrical and Electronic Engineering at ARROW@TU Dublin. It has been accepted for inclusion in Articles by an authorized administrator of ARROW@TU Dublin. For more information, please contact arrow.admin@tudublin.ie, aisling.coyne@tudublin.ie, gerard.connolly@tudublin.ie.

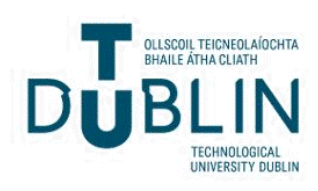




\section{Authors}

Samet Biricik, Shafiuzzaman Khadem, Soydan Redif, and Malabika Basu

This article is available at ARROW@TU Dublin: https://arrow.tudublin.ie/engscheleart2/143 
Voltage distortion mitigation in a distributed generation-integrated weak utility network via a self-tuning filter-based dynamic voltage restorer

\section{Samet Biricik, Shafiuzzaman}

\section{K. Khadem, Soydan Redif \& Malabika \\ Basu}

\section{Electrical Engineering}

Archiv für Elektrotechnik

ISSN 0948-7921

Volume 100

Number 3

Electr Eng (2018) 100:1857-1867 DOI 10.1007/s00202-017-0666-4

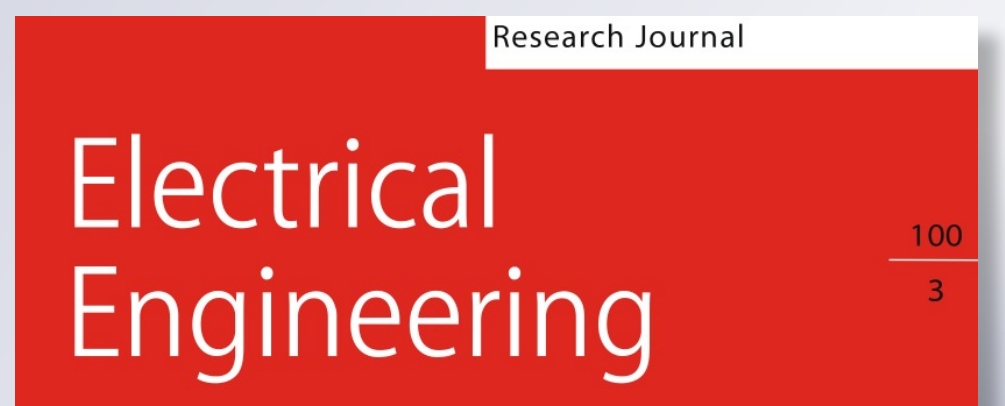

Archiv für Elektrotechnik

Dringer

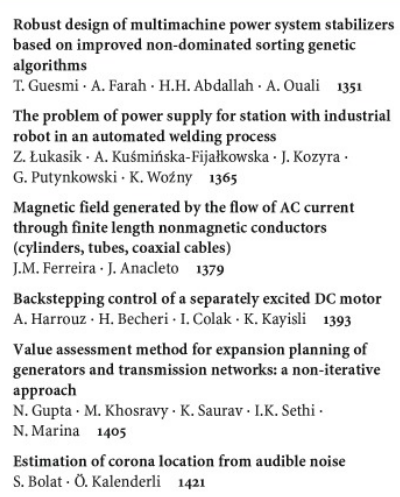

ORIGINAL PAPERS

Bat algorithm-based back propagation approach

for short-

S.S. Reddy $\quad 1297$

Electrical properties and aquatic ecotoxicity effects

of ZnS nanocrystals
A. Fkiri $\cdot$ N.B. Saber $~ B$ B. Sellami - A. Selmi $~ \cdot$ T. Altalhi .

A.A. Gobouri - A. Aldalbahi - A. Mezni 1305

Thermography and artificial intelligence in transformer
fault detection

G.M. dos Santos · R.R.B. de Aquino - M.M.S. Lira 1317

FPGA-in-the-loop simulation of a grid-connected

photovoltaic system by using a predictive control

H. Peregrina-Barreto $\cdot$ R. Morales-Caporal $\quad 1327$

Validation of single-phase transformer model

for ferroresonance analysis

J.A. Corea-Araujo - J.A. Martinez-Velasco .
F. González-Molina - J.A. Barrado-Rodrigo

L. Guasch-Pesquer $\cdot$ E. Castro-Aranda 1339

S. Bolat $\cdot 0$. Kalenderli 1421 
Your article is protected by copyright and all rights are held exclusively by SpringerVerlag GmbH Germany, part of Springer Nature. This e-offprint is for personal use only and shall not be self-archived in electronic repositories. If you wish to self-archive your article, please use the accepted manuscript version for posting on your own website. You may further deposit the accepted manuscript version in any repository, provided it is only made publicly available 12 months after official publication or later and provided acknowledgement is given to the original source of publication and a link is inserted to the published article on Springer's website. The link must be accompanied by the following text: "The final publication is available at link.springer.com". 


\title{
Voltage distortion mitigation in a distributed generation-integrated weak utility network via a self-tuning filter-based dynamic voltage restorer
}

\author{
Samet Biricik $^{1,2}$ (1) $\cdot$ Shafiuzzaman K. Khadem ${ }^{3} \cdot$ Soydan Redif $^{2} \cdot$ Malabika Basu $^{1}$
}

Received: 30 May 2017 / Accepted: 2 November 2017 / Published online: 15 November 2017

(C) Springer-Verlag GmbH Germany, part of Springer Nature 2017

\begin{abstract}
The dynamic voltage restorer (DVR) is mainly used in a utility grid to protect sensitive loads from power quality problems, such as voltage sags and swells. However, the effectiveness of the DVR can wane under unbalanced grid voltage conditions. Recently, DVR control algorithms have been developed that enable the elimination of voltage harmonics in weak and distorted utility networks. This paper presents a modified control method for the DVR, which can (1) compensate the voltage swell and (2) eliminate the voltage harmonics in a combined utility condition consisting of voltage unbalance and harmonic distortion. A self-tuning filter (STF) is used along with the pq control method to increase the control performance of the DVR. One of the advantages of STF is that it eliminates the need to have multiple filters as part of the control method, and thus reduces the controller complexity. Analysis of the fault ride-through capability of the new DVR revealed an improvement in the voltage stability offered to distributed generation-integrated weak utility networks. The proposed DVR control method is modeled in MATLAB/Simulink and tested in both off-line and real-time environments using the OPAL RT real-time platform. Results are then presented as a verification of the proposed system.
\end{abstract}

Keywords Dynamic voltage restorer - Self-tuning filter · Power quality improvement . Voltage sag and swell · Voltage harmonics

\section{Samet Biricik}

samet@biricikelektrik.com

1 School of Electrical and Electronic Engineering, Dublin Institute of Technology, Dublin, Ireland

2 Department of Electrical and Electronic Engineering, European University of Lefke, Mersin 10, Turkey

3 International Energy Research Centre, Tyndall National Institute, Dyke Parade, Cork, Ireland

\section{Introduction}

Integration and exploitation of distributed generation (DG) systems, such as uncontrollable renewable sources, which can maximize green energy penetration in the utility network, increases the concern of voltage and frequency stability. In addition, voltage distortions and fluctuations are also frequently encountered in weak utility network systems. Ripple currents due to the power electronics converters also cause voltage harmonics and, as a result, the utility voltage waveforms may become distorted. On the other hand, voltage sag and swell problems are usually caused by short-circuit current flowing into a fault. Voltage sags and swells are defined as a fast reduction or rise of utility voltages which can vary from 10 to $90 \%$ during sags and 110 to $180 \%$ during swells of its nominal value [1]. The presence of voltage harmonics in the power system is an important power quality problem and needs special attention in reducing its effect. In order to solve these voltage-related power quality problems, industrial and domestic users mostly use autotransformer-based voltage stabilizer [2]. However, mechanically controlled voltage stabilizers can only combat long duration voltage drops without reducing voltage harmonics. They respond sluggishly to voltage fluctuations and have a response time that is typically greater than $750 \mathrm{~ms}$. Therefore, this low-cost device would not be a viable solution for the case when there are fast voltage variations. The undesirable voltage fluctuations typically last for about $10 \mathrm{~ms}$ to $1 \mathrm{~min}$. Therefore, custom power devices (CPDs) play an important role in compensating for most power quality problems related to DG-integrated utility network systems [3,4].

A CPD that has been shown to alleviate voltage-related power quality problems while protecting sensitive loads is the dynamic voltage restorer (DVR). Although the main aim in using a DVR has been to compensate voltage sags and 
swells, there are three other uses of the DVR that may be performed while mitigating the voltage amplitude: alleviation of voltage harmonics, supplying reactive power to the load and compensating for phase jumps. The DVR is able to restore voltage-related problems in the distribution system [2]; it operates mainly as a voltage regulator, but also may act as a harmonic isolator between the load(s) and the utility system with a well-designed controller. It can also be used to filter harmonic voltages, reduce voltage flicker and regulate line voltage. In order to solve such voltage-related problems, the DVR uses stored energy to inject active power from the DC side to AC. The required elements on the DC side are the costliest and bulkiest parts of the system [3]. There are two methods mostly preferred in the supply of the required energy to the DC side. The first uses a rectifier that is directly fed from the grid [5] or the load terminal [6,7]; the second uses a battery energy storage system [8], which is either charged from the $\mathrm{AC}$ system or from a photovoltaic systems [2]. Performance of the DC supply through the DC link can further be improved by using the super capacitor at the dc terminal [9], but it then increases the overall cost of the system. A detailed comparative study for some of the DVR topologies is also found in [10].

In most of the DVR topologies, the control is based on the dq method $[3,7,8,11,12]$. In this type of system, the obtained $\mathrm{dq}$ voltages are subtracted from the reference voltages on the $\mathrm{dq}$ frame. Then, the obtained voltage error on the $\mathrm{dq}$ frame is converted to the three-phase abc system and injected to the system. The instantaneous active and reactive power theory (pq method) is also used in the control system of the DVR [13]. In most of the cases, focus has been given on the control of DVR for the effective compensation of voltage sags and/or voltage harmonics.

In $[2,11,14,15]$, control systems were developed with only voltage sag compensation in mind. In fact, to date, there has been very little development of DVR control algorithms for the compensation of both voltage sag/swell and harmonics $[7,8,16,17]$ in the literature. Moreover, much attention has been devoted to the design of power electronic devices that maintain synchronous operation under severe grid voltage fluctuations. This performance plays an important role in the operation of the inverter during system faults, termed the fault ride-through (FRT) capability of the system. In most cases, DVR simply compensates the voltage dip with a voltage phasor in series with the grid voltage phasor, whereas to achieve the FRT capability, one of the important point is that the series voltage of DVR needs to rotate in order to inject the reactive power into the grid. However, to the best of our knowledge, very little attention has been paid to testing of the DVR's FRT capability in real-time experiments [18-20]. In [20], an effective control of the DVR where digital all-pass filters are used for extracting the positive-sequence component from the unbalanced grid voltage and it applies for DFIG system. Ramirez et al. in [20] describes a solution for wind farms with squirrel cage asynchronous generators based on the use of a dynamic voltage restorer. It provides how the wind generator improves its ability to remain connected during a voltage disturbance and, at the same time, to fulfill the demanding reactive power requirements imposed by recent grid codes. In [21], authors recently proposed a combined Feed-Forward and Feed-Back (CFFFB)-based voltage control for DFIG also to improve performance of DVR in terms of voltage sag mitigation capability, active and reactive power support without tripping.

In this study, a control method is developed for both the compensation of voltage sag/swell and the suppression of voltage harmonic components on the load terminal. The proposed control system makes use of the self-tuning filter (STF) algorithm. Presently, the STF is used as part of the filtering mechanism for current harmonics in the controller of the three-wire shunt-connected active power filter (APF) [2224], hybrid APF [25,26] and in the controller of unified power quality conditioner (UPQC) [27]. More recently, in [28], it was shown that a single-phase version of STF can improve the harmonic suppression efficiency of the singlephase DVR in a distorted power system to suppress voltage anomalies using a sliding mode controller. Authors in [29] also proposed a simple STF solution for the control of the DVR operation in a three-phase system.

In this paper, we use the STF algorithm in order to enhance the control performance of the DVR in a three-phase system for the cases of non-ideal utility voltages and unbalanced voltage sag conditions. The proposed algorithm can also improve the voltage stability in the DG-integrated utility network. Additionally, we evaluate the performance of the DVR in terms of its fault ride-through capability.

The remainder of this paper has been organized as follows. The studied topology with the power circuit of the DVR is discussed in Sect. 2. The proposed control method featuring the STF is derived in Sect. 3. Development of a three-phase system and MATLAB simulation results are presented in Sect. 4. Section 5 presents real-time experimental results to verify the performance of the proposed method in a real environment. In Sect. 6, we provide a brief comparison of the required components and computation between the proposed method and a priori methods. Concluding remarks are given in Sect. 7 .

\section{Studied DVR topology}

The power circuit of the studied DVR is a three-phase Hbridge PWM converter having a dc battery group, as shown in Fig. 1. The battery group can be recharged using an external battery charger. In the studied system the associated control system does not require to regulate the dc link voltage. The ac side of the voltage source inverter (VSI) is connected to 


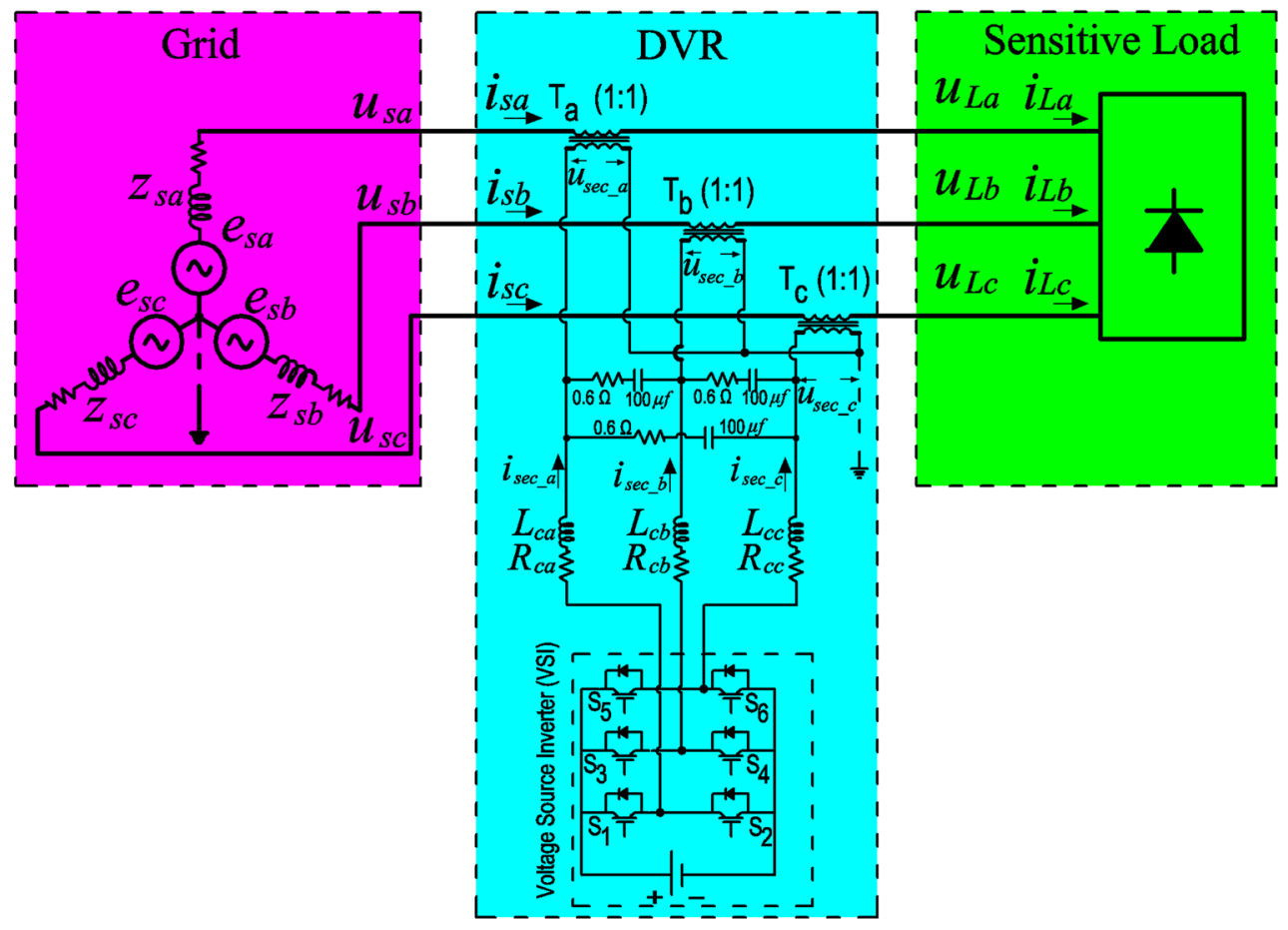

(a)

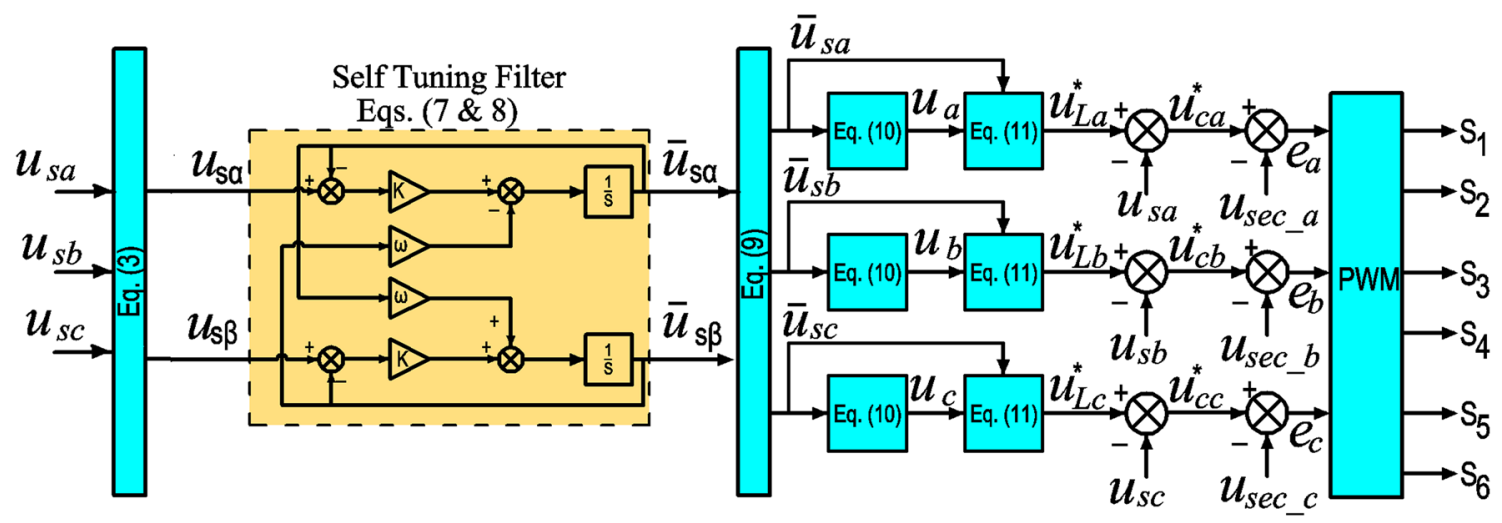

(b)

Fig. 1 a Schematic of the studied power circuit and DVR topology, b proposed control system of the studied DVR

the point of common coupling (PCC) through an inductor and three single-phase transformers.

The primary side of the transformers is connected in series between the utility and the load. The secondary sides of the transformers are connected in a delta [12] or star [8] configuration to the VSI. This type of connection is very useful during the compensation of unbalanced utility voltages [16]. Since the system is used for compensation of unbalances, the use of a grounded star point prevents zero-sequence voltages. For this reason, the star connection is preferred over the delta connection on the secondary side. The current through the secondary side of the transformer is measured by the current transformer $\left(\mathrm{CT}_{2}\right)$. In order to analyze the injected voltage by the control circuit of the DVR, the secondary side voltages of the transformers are also measured.

\section{Proposed control method}

The utility voltage is corrupted by voltage harmonics as well as voltage fluctuations, i.e., sagging and swelling of the voltage waveform. To verify performance of the proposed system, the source voltages are programmed as follows:

$u_{\mathrm{sa}}(t)=\sqrt{2}(230) \sin (\omega t)+30 \sin (5 \omega t)$ 


$$
\begin{aligned}
& +20 . \sin (7 \omega t)+7 \sin (11 \omega t) \\
& u_{\mathrm{sb}}(t)=\sqrt{2}(235) \sin \left(\omega t-\frac{2 \pi}{3}\right)+35 \sin \left(5 \omega t-\frac{2 \pi}{3}\right) \\
& +9 \sin \left(\omega t-\frac{2 \pi}{3}\right)+10 \sin \left(\omega t-\frac{3}{2 \pi}\right) \\
& u_{\mathrm{sc}}(t)=\underbrace{\sqrt{2}(222) \sin \left(\omega t-\frac{2 \pi}{3}\right)}_{\bar{u}_{\mathrm{s}}} \\
& +\underbrace{19 \sin \left(5 \omega t-\frac{2 \pi}{3}\right)+15 \sin \left(\omega t-\frac{2 \pi}{3}\right)+13 \sin \left(\omega t-\frac{2 \pi}{3}\right)}_{\tilde{u}_{\mathrm{s}}} .
\end{aligned}
$$

To achieve optimal performance from a device, the control system must be fed with an accurate reference signal. Therefore, the first aim of the studied DVR is the suppression of the voltage harmonics, $\tilde{u}_{\mathrm{s}}$. The DVR is also designed to regulate and balance the voltage amplitudes at the fundamental frequency, $\tilde{u}_{\mathrm{s}}$. The undistorted and balanced (ideal) voltages on the load terminal are given by

$$
\begin{aligned}
& u_{\mathrm{La}}(t)=\sqrt{2}(230) \sin (\omega t) \\
& u_{\mathrm{Lb}}(t)=\sqrt{2}(230) \sin \left(\omega t-\frac{2 \pi}{3}\right) \\
& u_{\mathrm{Lc}}(t)=\underbrace{\sqrt{2}(230) \sin \left(\omega t+\frac{2 \pi}{3}\right)}_{\tilde{u}_{s}} .
\end{aligned}
$$

As can be seen from (1) and (2), the DVR operates mainly as a voltage regulator and as a harmonic isolator between the source and load. The STF is adapted to this system in order to eliminate the voltage harmonics and estimate the voltage sags/swells in the supply side. This STF-based system can thus generate undistorted and balanced, two-phase voltage signals from the distorted grid voltages. For this, first the sensed utility voltages are transformed into a two-phase coordinate system using the Clarke (or $\alpha-\beta$ ) transformation, that is,

$$
\left[\begin{array}{l}
u_{s \alpha}(t) \\
u_{s \beta}(t)
\end{array}\right]=\sqrt{\frac{2}{3}}\left[\begin{array}{ccc}
1 & -\frac{1}{2} & -\frac{1}{2} \\
0 & \frac{\sqrt{3}}{2} & -\frac{\sqrt{3}}{2}
\end{array}\right]\left[\begin{array}{l}
u_{\mathrm{sa}}(t) \\
u_{\mathrm{sb}}(t) \\
u_{\mathrm{sc}}(t)
\end{array}\right]
$$

The $\alpha-\beta$ of the distorted utility voltages are processed by the STF. The transfer function of the STF is given by [22]:

$H(s)=\frac{V_{x y}(s)}{U_{x y}(s)}=\frac{s+j \omega}{s^{2}+\omega^{2}}$,

where

$$
V_{x y}(t)=e^{j \omega} \int e^{-j \omega} U_{x y}(t) d t .
$$

The response of the STF is similar to that of a general band-pass filter. Apart from the integral effect on the input magnitude, the phase of the output waveform is the same as the input signal waveform [22]. In order to have unit magnitude, a constant $K$ value is applied to (4), thus

$H(s)=\frac{V_{x y}(s)}{U_{x y}(s)}=K \frac{(s+K)+j \omega}{(s+K)^{2}+\omega^{2}}$.

The signals generated by (3) are then transformed by the STF, which generates the two-phase, instantaneous, undistorted signals, in terms of $\alpha-\beta$, i.e.,

$\bar{u}_{s \alpha}(s)=\frac{K}{s}\left[u_{s \alpha}(s)-\bar{u}_{s \alpha}(s)\right]-\frac{\omega}{s} \bar{u}_{s \beta}(s)$,
$\bar{u}_{s \beta}(s)=\frac{K}{s}\left[u_{s \beta}(s)-\bar{u}_{s \beta}(s)\right]+\frac{\omega}{s} \bar{u}_{s \alpha}(s)$.

The obtained undistorted and balanced two-phase voltages can then be converted to the three-phase system by using the inverse Clark transformation, given by

$$
\left[\begin{array}{l}
\bar{u}_{\mathrm{sa}}(t) \\
\bar{u}_{\mathrm{sb}}(t) \\
\bar{u}_{\mathrm{sc}}(t)
\end{array}\right]=\sqrt{\frac{3}{2}}\left[\begin{array}{cc}
0 & 1 \\
\frac{\sqrt{3}}{2} & -\frac{1}{2} \\
-\frac{\sqrt{3}}{2} & -\frac{1}{2}
\end{array}\right]\left[\begin{array}{l}
\bar{u}_{s \alpha}(t) \\
\bar{u}_{s \beta}(t)
\end{array}\right] .
$$

The voltages obtained from (9) are voltages at the fundamental harmonic $(50 \mathrm{~Hz})$. However, the output signals from (9) will be corrupted by voltage sags and/or swells due to the voltage fluctuations on the utility voltages. Therefore, these signals cannot be used as reference voltage signals. In order to obtain a reference voltage waveform for each phase, the voltages obtained in (9) are normalized by the amplitudes of the voltages in (9), namely $U_{\mathrm{sa}}^{\prime}, U_{\mathrm{sb}}^{\prime}$, and $U_{\mathrm{sc}}^{\prime}$, i.e.,

$$
\left.\begin{array}{l}
v_{\mathrm{a}}(t)=\sin (\omega t)=\frac{\bar{u}_{\mathrm{sa}}(t)}{U_{\mathrm{sa}}^{\prime}} \\
v_{\mathrm{b}}(t)=\sin \left(\omega t-\frac{2 \pi}{3}\right)=\frac{\bar{u}_{\mathrm{sb}}(t)}{U_{\mathrm{sb}}^{\prime}} \\
v_{\mathrm{c}}(t)=\sin \left(\omega t+\frac{2 \pi}{3}\right)=\frac{\bar{u}_{\mathrm{sc}}(t)}{U_{\mathrm{sc}}^{\prime}}
\end{array}\right\} .
$$

This method can be used to determine unity sine functions, each phase of which varies between $+1 \mathrm{~V}$ and $-1 \mathrm{~V}$. Finally, the reference utility voltages can be calculated by multiplying the desired amplitude of the utility voltage, which is $\sqrt{2} \times 230$ in the studied system, with the unity sine function; that is,

$$
\left.\begin{array}{l}
u_{\mathrm{La}}^{*}(t)=\sqrt{3} \times 230 v_{\mathrm{a}}(t) \\
u_{\mathrm{Lb}}^{*}(t)=\sqrt{3} \times 230 v_{\mathrm{b}}(t) \\
u_{\mathrm{Lc}}^{*}(t)=\sqrt{3} \times 230 v_{\mathrm{c}}(t)
\end{array}\right\},
$$

where the voltages are balanced at a level of $\sqrt{3} \times 230$ and purely sinusoidal at a frequency of $50 \mathrm{~Hz}$. Then, the required reference compensation voltages, $u_{\mathrm{c}}^{*}(t)$, which are induced over the secondary side of the transformer, can be determined 
by difference between the voltages in (11) and the measured utility voltages in (1), that is,

$u_{\mathrm{ca}}^{*}(t)=u_{\mathrm{sa}}(t)-u_{\mathrm{La}}^{*}(t)$

$\left.u_{\mathrm{cb}}^{*}(t)=u_{\mathrm{sb}}(t)-u_{\mathrm{Lb}}^{*}(t)\right\}$.

$\left.u_{\mathrm{cc}}^{*}(t)=u_{\mathrm{sc}}(t)-u_{\mathrm{Lc}}^{*}(t)\right\}$

Under ideal conditions, the result in (12) means that the source voltages, in (2), will be zero. Therefore, the DVR converter will turn off. However, during a voltage sag, $u_{\text {sag }}$, and harmonic voltage pollution $\left(\bar{u}_{\mathrm{s}}\right)$ on the source, $(12)$ becomes

$u_{\mathrm{ca}}^{*}(t)=u_{\text {sag_a }}(t)+\tilde{u}_{\mathrm{sa}}(t)$

$\left.u_{\mathrm{cb}}^{*}(t)=u_{\mathrm{sag} \_\mathrm{b}}(t)+\tilde{u}_{\mathrm{sb}}(t)\right\}$.

$\left.u_{\mathrm{cc}}^{*}(t)=u_{\mathrm{sag} \_\mathrm{c}}(t)+\tilde{u}_{\mathrm{sc}}(t)\right\}$

These reference voltages are used to compute the signals that drive the VSI switches, which are actually error voltages, computed as the difference between the voltages in (13) and the measured (induced) voltages on the secondary side of the transformer, $u_{\mathrm{sec}}(t)$. That is,

$e_{\mathrm{a}}(t)=u_{\mathrm{ca}}^{*}(t)-u_{\mathrm{sec} \_\mathrm{a}}(t)$

$\left.e_{\mathrm{b}}(t)=u_{\mathrm{cb}}^{*}(t)-u_{\mathrm{sec}_{-} \mathrm{b}}(t)\right\}$,

$\left.e_{\mathrm{c}}(t)=u_{\mathrm{cc}}^{*}(t)-u_{\text {sec_c }_{-}}(t)\right\}$

where $e_{\mathrm{a}}(t), e_{\mathrm{b}}(t)$ and $e_{\mathrm{c}}(t)$ are the error voltages. The determined errors for each phase in (14) are used to drive the VSI switches with the generated PWM pulses. Figure 2 shows the block diagram of the proposed controller.

\section{Simulation results}

To demonstrate the performance of the proposed control system, we define a three-phase power system simulation scenario using MATLAB/Simulink, as shown in Fig. 1a. The block diagram of the studied three-phase control system is presented in Fig. 1b. The parameters used for the system are based on those from [30] and are given in Table 1. The performance of the proposed control system is investigated under distorted (voltage sags/swells), unbalanced utility voltage conditions and with a combination of linear and nonlinear loads. This allows for a performance analysis of the disturbances on both the utility side and the load side. Table 2 shows the values of important test conditions of the distribution network.

In order to verify performance of the proposed system under different load combinations, the load groups were modeled such that they draw active and reactive currents as well as non-sinusoidal currents from the utility. For this reason, Load 1 (linear Load) was used to draw active power with reactive power from the utility. However, Load 2 and Load

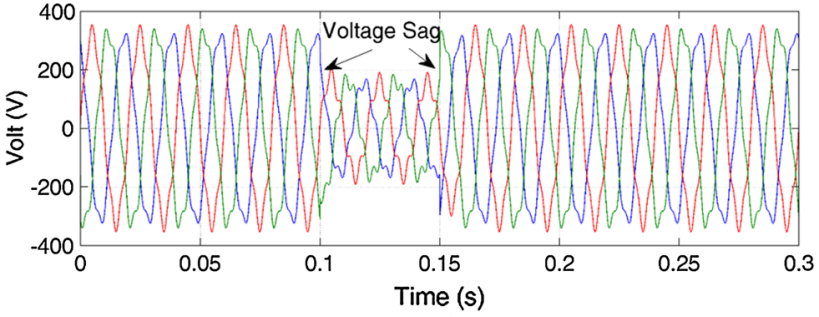

(a)

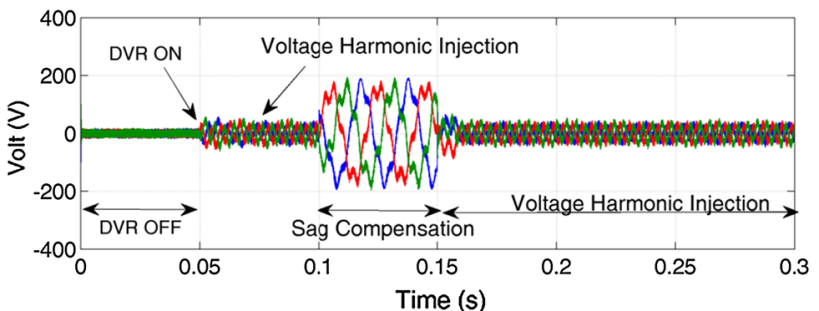

(b)

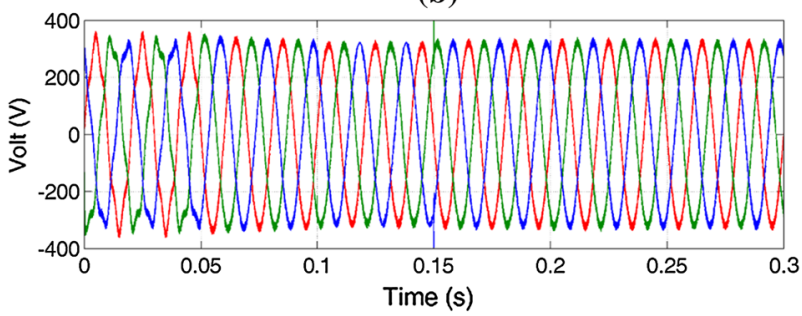

(c)

Fig. 2 a Unbalanced and distorted three-phase utility voltages, $\mathbf{b}$ threephase voltages injected by the DVR, $\mathbf{c}$ resultant three-phase voltages at the load terminal

Table 1 System parameters

\begin{tabular}{lll}
\hline Symbol & Quantity & Value \\
\hline$v_{\mathrm{S}}$ & Ideal utility rms voltage (L-N) & $230 \mathrm{~V}$ \\
$f$ & Utility frequency & $50 \mathrm{~Hz}$ \\
$Z s$ & Source impedance & $0.5 \Omega, 0.1 \mathrm{mH}$ \\
Load $_{1}$ & Linear load res. and ind. & $4 \Omega, 10 \mathrm{mH}$ \\
Load $_{2}$ & Nonlinear load res. and ind. & $7.5 \Omega, 45 \mathrm{mH}$ \\
Load $_{3}$ & Nonlinear load res. and ind. & $24 \Omega, 15 \mathrm{mH}$ \\
Lc & Filter inductor & $0.3 \mathrm{mH}$ \\
$U_{\mathrm{dc}}$ & dc link source voltage & $600 \mathrm{~V}$ \\
$\mathrm{f}_{\mathrm{S}}$ & Switching frequency & $10 \mathrm{kHz}$ \\
$\mathrm{TS}$ & Sampling time & $20 \mu \mathrm{S}$ \\
$\mathrm{K}$ & STF gain & 50 \\
\hline
\end{tabular}

Table 2 Test conditions of the distributed network

\begin{tabular}{lll}
\hline Disturbances & Conditions & Max value \\
\hline Utility side & Voltage harmonics & $\sim 10 \%$ \\
& Voltage sag & $50 \%$ \\
& Voltage unbalance & $3 \%$ \\
Load side & Current harmonics & $18 \%$ \\
\hline
\end{tabular}


Table 3 Operation time

\begin{tabular}{lllllll}
\hline Condition & \multicolumn{7}{l}{ Time (s) } & & & \\
\cline { 2 - 6 } & $0-0.05$ & $0.05-0.1$ & $0.1-0.15$ & $0.15-0.2$ & $0.2-0.25$ & $0.25-0.3$ \\
\hline Utility side & & & & & \\
Voltage harmonics & $9.05 \%$ & $9.05 \%$ & $17.89 \%$ & $9.05 \%$ & $9.05 \%$ & $9.05 \%$ \\
Voltage unbalance & $3 \%$ & $3 \%$ & $3 \%$ & $3 \%$ & $3 \%$ & $3 \%$ \\
Voltage sag & $0 \%$ & $0 \%$ & $50 \%$ & $0 \%$ & $0 \%$ & $0 \%$ \\
DVR & OFF & ON & ON & ON & ON & ON \\
Load side & & & & & & $3.50 \%$ \\
Voltage harmonics & $9.76 \%$ & $3.60 \%$ & $2.87 \%$ & $3.82 \%$ & $3.42 \%$ \\
Voltage unbalance & $3 \%$ & $0.9 \%$ & $0 \%$ & $0 \%$ & $0 \%$ & $0 \%$ \\
Voltage sag & $0 \%$ & $0 \%$ & $0.062 \%$ & $0 \%$ & $0 \%$ & $0 \%$ \\
\hline
\end{tabular}

3 (nonlinear loads) were designed as power electronics elements used to consume harmonic currents. Each nonlinear load was fed by a three-phase, uncontrolled bridge rectifier, using six diodes. Therefore, the dominant harmonics are the 5th and 7th harmonics. The 3rd harmonic was considerably weaker in comparison. The simulation is run for $0-0.3 \mathrm{~s}$ and the dynamic performance of the proposed system is also obtained by changing the load in a specified time. Table 3 gives details about the duration of the disturbances and their effect along with the response time of the DVR and its performance.

\subsection{Utility side disturbances}

The system is operated under the non-ideal utility voltage condition (including harmonics and unbalances), which is representative of the weak utility condition. An example of the distorted three-phase utility voltage waveforms is shown in Fig. 2a. The total harmonic distortion (THD) of the utility voltages, for each phase, is $9.06,9.65$ and $7.39 \%$. The rms values of the unbalanced phase voltages are 229.4, 231.9, 225.4 V. As shown in Fig. 2 a and given in Tables 2 and 3, the simulation runs for $0.3 \mathrm{~s}$, and a $50 \%$ sag is applied between 0.1 and $0.15 \mathrm{~s}$. Therefore, the utility voltages are reduced to $116.9,116.9$ and $110.4 \mathrm{~V}$. The performance of the proposed method is observed in Fig. 2b, where the DVR injects the required voltage to compensate for the voltage sag. Figure $3 \mathrm{c}$ shows the three-phase voltages after DVR processing. A striking result is that the voltages at the load terminal are balanced, to a good degree, and have very little distortion. The voltage harmonics at the PCC are reduced from $10 \%$ to around $\sim 3 \%$, and the rms voltages have been improved from 116 to $230 \mathrm{~V}$.

\subsection{Load side disturbance}

The THD of the load currents in each phase have been found to be $19.36,19.07$ and $19.64 \%$, while the currents are 108.8 ,

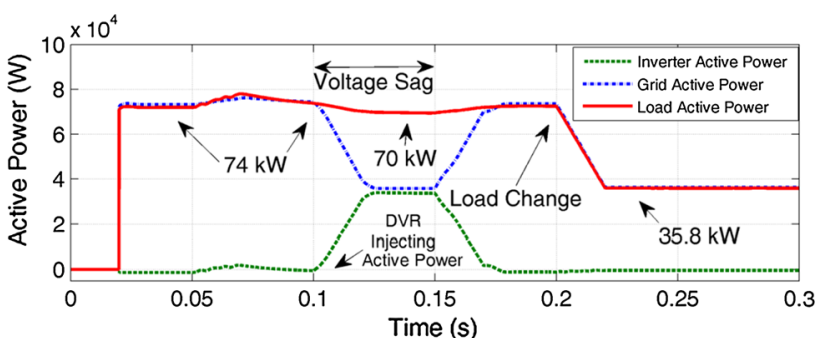

(a)

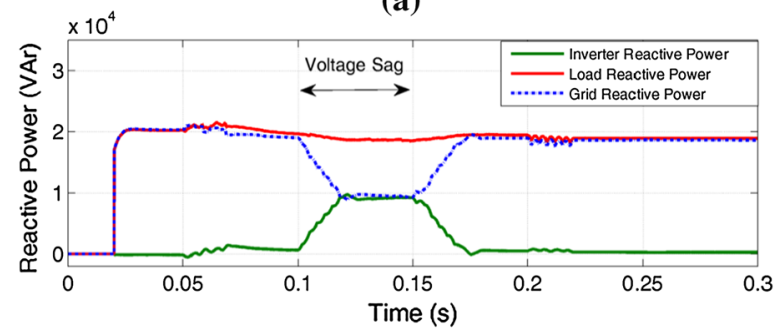

(b)

Fig. 3 Analysis of the powers consumed: a active power, $\mathbf{b}$ reactive power

$109.8,108.5 \mathrm{~A}$. Voltage change on the utility side is created by reducing the utility current to $59.34,59.46,59.27 \mathrm{~A}$. This is observed in the period $0.1-0.15 \mathrm{~s}$. However, there is little effect on the load groups by the voltage disturbances, as can be seen in Fig. 3a and b.

The system performance during the load changes has also been studied. The load variation is applied after $0.20 \mathrm{~s}$, as shown in Fig. 3a and b. The performance of the DVR is observed in Fig. 2c, where it is found that DVR still compensates the voltage harmonics without any interruption. Consequently, the voltage at PCC is found to be stable. Figure 3 can also be used to verify the performance of the system in terms of power management. It was found that, under full-load conditions, the consumed active power was around $70 \mathrm{~kW}$ and the total reactive power was $20 \mathrm{kVAr}$ - see Fig. $3 \mathrm{a}$ and $\mathrm{b}$. During the period where the voltage sagged, the consumed active power from the utility reduced to 38 
$\mathrm{kW}$ and the total reactive power reduced to $12 \mathrm{kVAr}$ on the utility side. This reduction can be seen in Fig. 3a, denoted by the blue line, and Fig. 3b, represented by the green line, in the period $0.05-0.10 \mathrm{~s}$, respectively. However, the proposed method dynamically compensated the active and reactivate power, as represented by the red line in Fig. 3a and b. As a result, the load groups do not experience any power changes during any kind of voltage disturbances on the utility.

\subsection{Fault ride-through capability}

In this subsection, a test is carried out in order to verify the FRT capability of the proposed system against a three-phase fault at the grid. The FRT of the DVR is the capability to restore and maintain the load terminal voltage at desired level in case of a fault occurs in the grid for a short period of time. The simulation results in Fig. 4 show the grid voltage under three types of fault: a three-phase fault, single-phaseto-ground fault and phase-to-phase fault at the grid. The DVR injects the required compensation voltages to minimize the effect of faults at the load terminal as presented in Fig. $4 \mathrm{~b}$. As a result of this, the voltages at the load terminal are compensated during the faults as seen in Fig. $4 \mathrm{c}$. It is obvious that the fault is cleared and the load voltages are restored quickly.

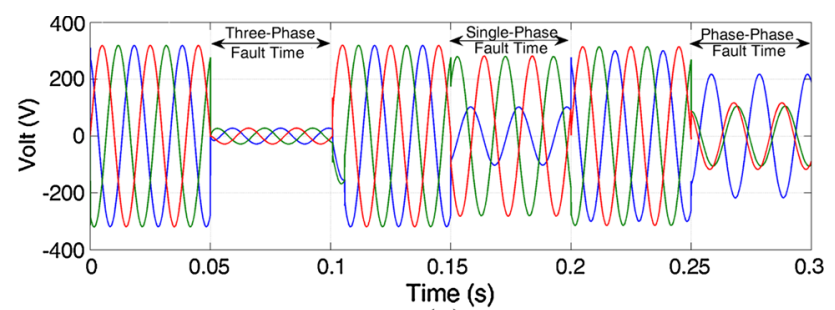

(a)

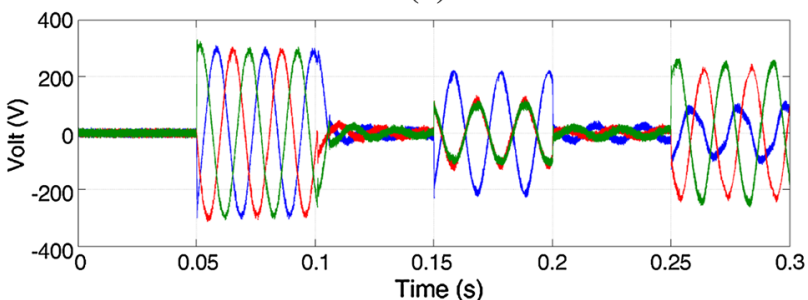

(b)

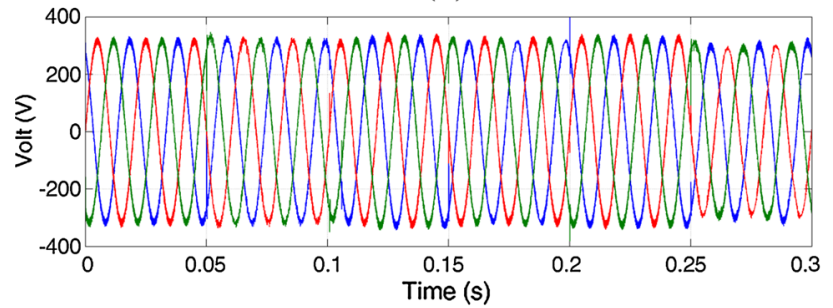

(c)

Fig. 4 Performance of the proposed system under three-phase-toground fault, Single-phase-to-ground fault and phase-to-phase fault a three-phase utility voltages, $\mathbf{b}$ three-phase voltages injected by the DVR, c resultant three-phase voltages at the load terminal

\section{Laboratory experiments}

To demonstrate the performance of the proposed control system in a real-time environment, real-time simulation of the power system, modeled in Simulink, was performed on the RT-LAB platform. Software-in-the-loop (SIL) was utilized to verify the correct operation of our control system; real-time communications between the sensing and control signals was achieved using hardware synchronization mode $[24,30]$. Figures 5, 6, 7 and 8 show the real-time performance analysis of the proposed method under three different utility voltage cases. Table 4 shows the measurement results, for both the utility side and the load side, under three different cases:

A) Utility voltage waveforms are unbalanced and distorted

B) Voltage sag condition is applied to phase A only

C) Reduced voltage at phase B and C, where phase A is in standard condition

\subsection{Case A}

Figure 5a shows the utility voltage waveforms, which are clearly unbalanced and distorted. The injected voltages by the DVR can be seen in Fig. 5b. Figure 6c shows the undistorted and balanced three-phase voltages at the load terminal. In this case, phase-neutral voltages are fixed to $230 \mathrm{~V}$, and voltage harmonics are reduced to around $3 \%$, as given in the first row of Table 3.

\subsection{Case B}

In this case, single-phase voltage sags are applied to phase A. As a result, the utility voltage at phase A reduces to 120 $\mathrm{V}$ (Fig. 6a), while phase $\mathrm{B}$ and phase $\mathrm{C}$ are still unbalanced; and voltage harmonics are at around $10 \%$. For this case, we observe that the proposed STF-based DVR compensates for the voltage harmonics without interruption during voltage sags - see Fig. 6c. The THD of the load voltages, in each phase, are found to be $2.81,4.29$ and $3.56 \%$, for a voltage of $225 \mathrm{~V}$ in each phases.

\subsection{Case C}

As can be seen in Fig. 7a, phase B and phase C utility voltages were reduced by up to 135 and $122 \mathrm{~V}$, respectively. However, phase A was maintained at the required voltage level. The voltages produced by the proposed DVR control system is shown in Fig. 7b. From Fig. 7c, we see that the corruption of the load voltages has been significantly reduced, which is as a result of injection of the required voltages to the PCC by the DVR. The voltage harmonics at the PCC are reduced from $10 \%$ to around $4 \%$ and the rms voltages are improved from 116 to $225 \mathrm{~V}$. 


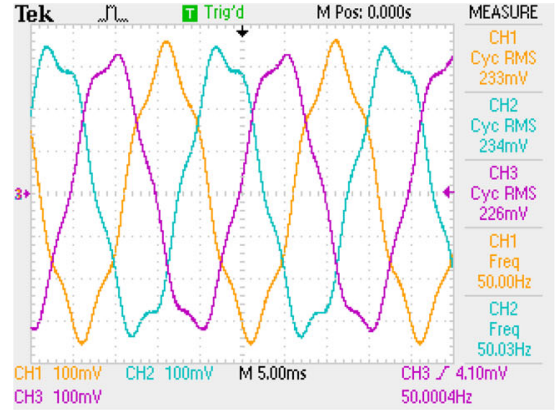

(a)

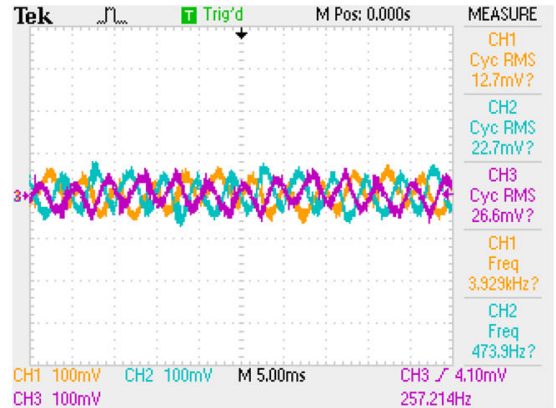

(b)

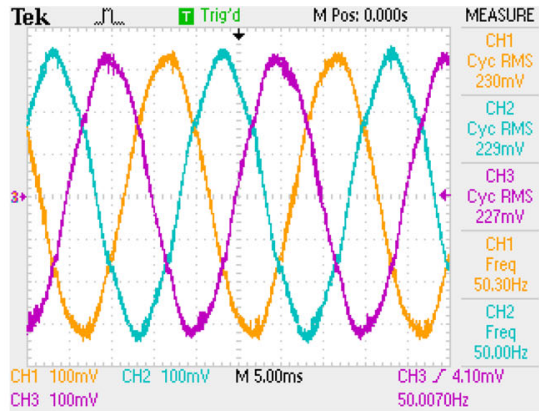

(c)

Fig. 5 Experimental results for Case A, a distorted and unbalanced utility voltages, $\mathbf{b}$ injected voltages by the DVR, $\mathbf{c}$ the resultant voltages at the PCC terminal (100 V/div)

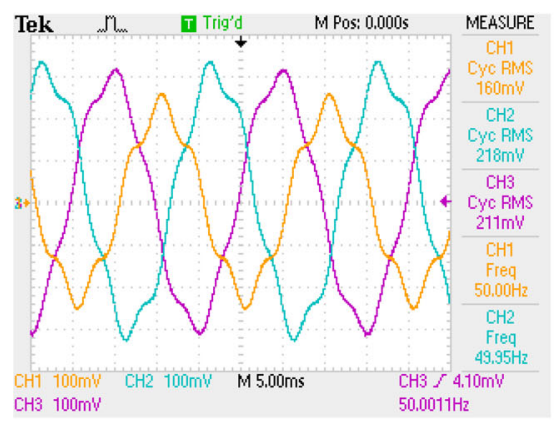

(a)

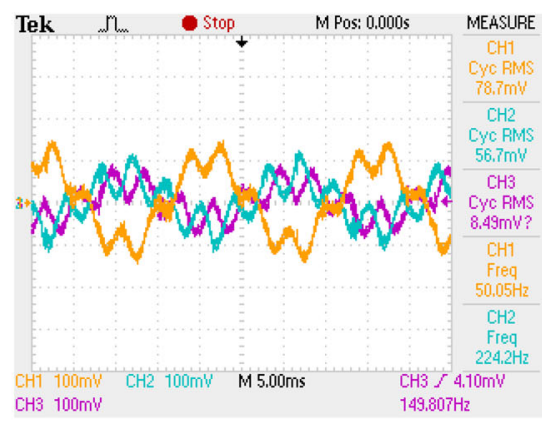

(b)

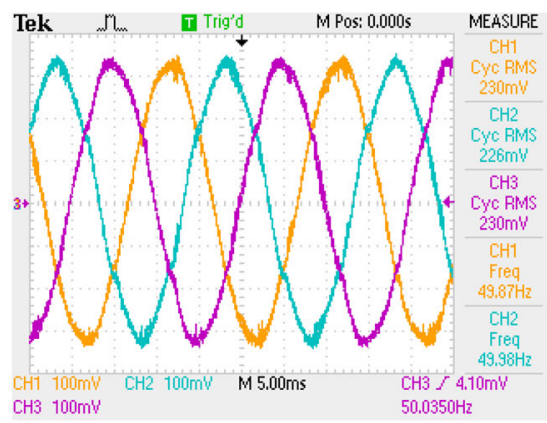

(c)

Fig. 6 Experimental results for Case B, a distorted and unbalanced utility voltages, $\mathbf{b}$ injected voltages by the DVR, $\mathbf{c}$ the obtained undistorted and balanced voltages at PCC terminal (100 V/div)

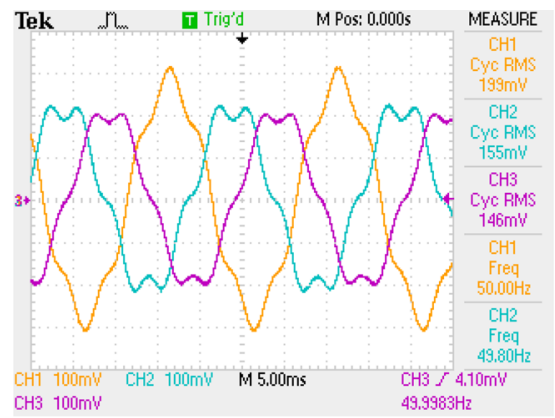

(a)

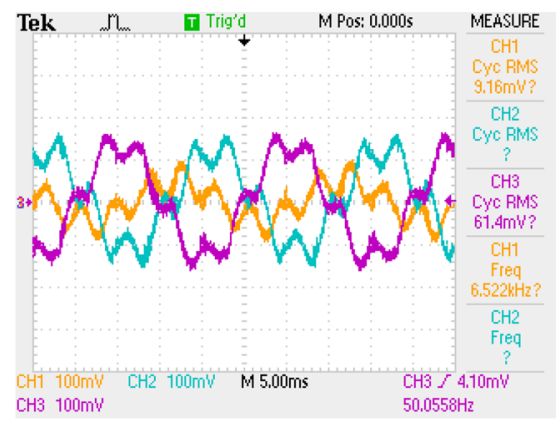

(b)

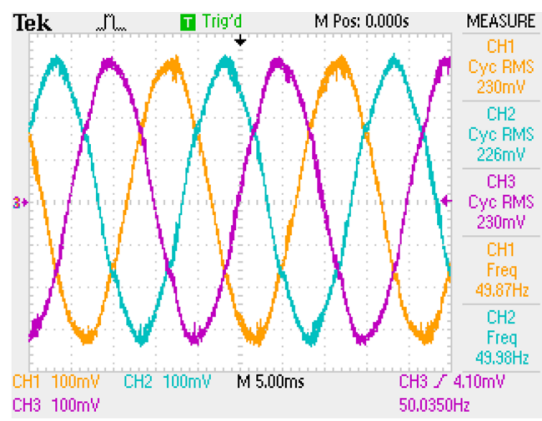

(c)

Fig. 7 Experimental results for Case C, a distorted and unbalanced utility voltages, $\mathbf{b}$ injected voltages by the DVR, $\mathbf{c}$ the obtained undistorted and balanced voltages at PCC terminal $(100 \mathrm{~V} /$ div $)$

\subsection{System response}

The response of a DVR controller to sudden supply voltage degradations is of paramount importance in maintaining a high-quality utility network. To assess the response of the proposed control method, the real-time response of our STFbased DVR controller is shown in Fig. 8. The response was obtained by switching on the DVR during a period where the utility voltage suffered a worst-case scenario, comprising a combination of voltage distortions at the PCC: voltage disturbance, unbalance voltage and voltage sags. Required system response time is specified by the Information Technology Industry Council (ITIC) and Computer Business Equipment Manufacturers Association (CBEMA) [1,16]. In Fig. 8, we see that the DVR possesses a very fast response, e.g., 5$20 \mathrm{~ms}$, responding to disturbances before they can adversely affect the utility network. This high-speed response is mainly attributed to the simplicity of the proposed control method. However, it is important to mention that the response time of the voltage is not the only essential parameter. The restoring time on the consumed power is also critical in understanding the performance of the system. In Fig.3, we see that the 


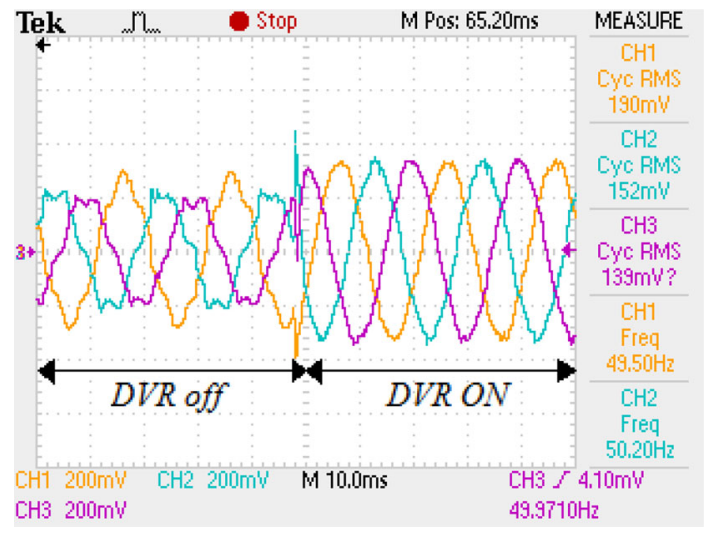

Fig. 8 Response of the proposed DVR controller during utility voltage distortion $(200 \mathrm{~V} /$ div $)$

studied system can restore the consumed power within 15 ms.

\section{Comparison of the proposed control method with state of the art}

It is well known that the occurrence and intensity of voltagerelated harmonics has increased, over the years, in utility systems and industrial power systems; this is largely due to the increase in the number of voltage harmonic-generating devices. In order to overcome these voltage-related power quality problems, several DVR topologies and control methods have been investigated in the literature. In Table 5, we provide a comparison of the proposed method with stateof-the-art systems in terms of the defining features of each method. Special attention has been given on the requirement of DC sources, method to detect voltage harmonics, computational complexity in terms of required transformations, use of uncontrollable/unadaptable filters and using additional controller (such as PI controller). Along with these, the functional capability of DVR for each of the compared papers are also reviewed. It was found that the solutions in $[2,9,15]$ only compensate for voltage sags and swells, which is usually not adequate. In contrast, the STF-based DVR method not only rectifies voltage sags/swells but also suppresses voltage harmonics on the load terminal and mitigates grid disturbances. In addition, the proposed method uses and tunes a simple STF to improve its performance on achieving FRT capability. These methods use PLL and one (or more) low-pass filters (LPF) in order to detect and suppress voltage harmonics. However, the greatest disadvantage of these methods is that

Table 4 Utility and load side measurements

\begin{tabular}{|c|c|c|c|c|c|c|c|c|c|c|c|c|}
\hline \multirow[t]{3}{*}{ Cases } & \multicolumn{6}{|c|}{ Utility side } & \multicolumn{6}{|c|}{ Load side } \\
\hline & \multicolumn{3}{|c|}{ L-N voltage $(\mathrm{V})$} & \multicolumn{3}{|c|}{ Voltage THD (\%) } & \multicolumn{3}{|c|}{ L-N voltage $(\mathrm{V})$} & \multicolumn{3}{|c|}{ Voltage THD (\%) } \\
\hline & $U_{\mathrm{an}}$ & $U_{\mathrm{bn}}$ & $U_{\mathrm{cn}}$ & $U_{\mathrm{an}}$ & $U_{\mathrm{bn}}$ & $U_{\mathrm{cn}}$ & $U_{\text {an }}$ & $U_{\mathrm{bn}}$ & $U_{\mathrm{cn}}$ & $U_{\text {an }}$ & $U_{\mathrm{bn}}$ & $U_{\mathrm{cn}}$ \\
\hline A (Fig. 6) & 230 & 235 & 222 & 9.05 & 9.65 & 7.38 & 230 & 230 & 230 & 2.77 & 4.34 & 3.42 \\
\hline B (Fig. 7) & 120 & 235 & 222 & 13.30 & 10.38 & 7.94 & 225 & 225 & 230 & 2.81 & 4.29 & 3.56 \\
\hline C (Fig. 8) & 230 & 135 & 122 & 10.59 & 14.74 & 11.50 & 230 & 230 & 230 & 2.78 & 4.35 & 3.43 \\
\hline
\end{tabular}

Table 5 Comparison of the proposed DVR with some other methods

\begin{tabular}{|c|c|c|c|c|c|}
\hline $\begin{array}{l}\text { Compared } \\
\text { aspects }\end{array}$ & Proposed method & Ramasamy and Thangavel [2] & Jayaprakash et al. [8] & Omar and Rahim [9] & Teke et al. [15] \\
\hline DC-source & Optional & PV-based & & PV-based & Battery storage \\
\hline $\begin{array}{l}\text { Voltage harmonic } \\
\text { detection }\end{array}$ & Self-tuning filter & Cannot filter harmonics & LPF & Cannot filter harmonics & $\begin{array}{c}\text { Cannot filter } \\
\text { harmonics }\end{array}$ \\
\hline $\begin{array}{l}\text { Clarke } \\
\text { transformation }\end{array}$ & 1 & 0 & 0 & 1 & 0 \\
\hline $\begin{array}{l}\text { Inverse Clarke } \\
\text { transformation }\end{array}$ & 1 & 0 & 0 & 1 & 0 \\
\hline $\begin{array}{l}\text { abc/dq } \\
\text { Transformation }\end{array}$ & 0 & 1 & 3 & 1 & 1 \\
\hline $\begin{array}{l}\mathrm{dq} / \mathrm{abc} \\
\text { transformation }\end{array}$ & 0 & 0 & 1 & 1 & 0 \\
\hline PLL & 0 & 1 & 1 & 1 & 1 \\
\hline LPF & 0 & $1^{*}$ at the DC-DC converter & 3 & 2 & 1 \\
\hline PI & 0 & 1 & 2 & 2 & 0 \\
\hline $\begin{array}{r}\text { Amplitude } \\
\text { detection }\end{array}$ & 1 & 1. & 1 & 1 & 1 \\
\hline
\end{tabular}


the LPFs cannot adapt to changes. They also require a large number of other components, giving it an inherent processing delay. As a consequence, it would be unable to track and generate reference compensating waveforms properly.

Reported control algorithms are mostly complex and sluggish $[2,8,9,15]$. Investigation of the prior art reveals that our method provides a simpler solution with fewer parameters to set up, making it more cost effective and computationally efficient. Due to its simplicity, the proposed system has a fast dynamic response and can perform online estimation of voltage anomalies, requiring a much lower number of operations, as demonstrated in Sects. 4 and 5. These are highly desirable qualities in a world where there is an increasing demand for cheap solutions to power quality problems that arise from rapidly changing loads and sensitive devices.

\section{Conclusion}

In this paper, we have investigated control methods for the dynamic voltage restorer (DVR) with the aim of improving the voltage quality of the utility grid. Specifically, we use the self-tuning filter (STF) to improve the DVRs ability in producing an accurate and stable control reference voltage for combating voltage sags/swells and voltage harmonics for distorted, unbalanced utility voltages and nonlinear loads. Compared to the prior art methods for voltage distortion compensation, the STF-based DVR control method is simple in structure, requiring fewer components and eliminating the need for low-pass or high-pass filters, and computationally efficient. Practical benefits of the proposed control method are highlighted through computer simulation in a real-time environment. Results show that the STF-based DVR system boasts a fast response time, suppressing voltage harmonics and disturbances before they have time to disrupt the utility network.

\section{References}

1. Dugan RC, McGranaghan MF, Beaty HW (2009) Electrical power systems quality. McGraw-Hill, New York

2. Ramasamy M, Thangavel S (2013) Experimental verification of PV based dynamic voltage restorer (PV-DVR) with significant energy conservation. Int J Electr Power Energy Syst 49:296-307

3. Babaei E, Kangarlu MF (2011) Voltage quality improvement by a dynamic voltage restorer based on a direct three-phase converter with fictitious DC link. IET Gener Transm Distrib 5(8):814-823

4. Khadem SK, Basu M, Conlon MF (2010) Power quality in grid connected renewable energy systems: role of custom power devices. In: International conference on renewable energy and power quality (ICREPQ). Granada, Spain, 23-25 March 2010

5. Lam C-S, Wong M-C, Han Y-D (2008) Voltage swell and overvoltage compensation with unidirectional power flow controlled dynamic voltage restorer. IEEE Trans Power Del 23(4):2513-2521
6. Jimichi T, Fujita H, Akagi H (2008) Design and experimentation of a dynamic voltage restorer capable of significantly reducing an energy-storage element. IEEE Trans Ind Appl 44(3):817-825

7. Komurcugil H, Biricik S (2017) Time-varying and constant switching frequency based sliding mode control methods for transformerless dvr employing half-bridge VSI. IEEE Trans Ind Electron 64(4):2570-2579

8. Jowder FAL (2009) Design and analysis of dynamic voltage restorer for deep voltage sag and harmonic compensation. IET Gener Transm Distrib 3(6):547-560

9. Omar R, Rahim NA (2012) Voltage unbalanced compensation using dynamic voltage restorer based on supercapacitor. Int J Electr Power Energy Syst 43(1):573-581

10. Nielsen JG, Blaabjerg F (2005) A detailed comparison of system topologies for dynamic voltage restorers. IEEE Trans Ind Appl 41(5):1272-1280

11. Chen W-L, Wang M-J (2014) Control design of a dynamic voltage restorer for wind-driven induction generators during a low voltage fault at grid bus. Electr Power Compon Syst 42(14):1553-1564

12. Inci M, Bayındir KC, Tumay M (2016) Improved synchronous reference frame based controller method for multifunctional compensation. Electr Power Syst Res 141:500-509

13. Mulla MA, Rajagopalan C, Chowdhury A (2013) Hardware implementation of series hybrid active power filter using a novel control strategy based on generalised instantaneous power theory. IET Power Electron 6(3):592-600

14. Mahinda VD, Wijekoon HM, Choi SS (2003) A novel dynamic series compensator with closed-loop voltage and current mode control for voltage sag mitigation. Int J Electron 90(11-12):695-706

15. Teke A, Bayindir K, Tumay M (2010) Fast sag/swell detection method for fuzzy logic controlled dynamic voltage restorer. IET Gener Transm Distrib 4(1):1-12

16. Abdollahzadeh H, Jazaeri M, Tavighi A (2014) A new fastconverged estimation approach for dynamic voltage restorer (DVR) to compensate voltage sags in waveform distortion conditions. Int J Electr Power Energy Syst 54:598-609

17. Sadigh AK, Smedley KM (2016) Fast and precise voltage sag detection method for dynamic voltage restorer (DVR) application. Electr Power Syst Res 130:192-207

18. Hussein AA, Ali MH (2014) Comparison between DVR and SFCL for fault ride through capability improvement of fixed-speed wind generator. In: IEEE PES T\&D conference and exposition. pp 1-5

19. Ramirez D, Martinez S, Platero CA, Blazquez F, De Castro RM (2011) Low-voltage ride-through capability for wind generators based on dynamic voltage restorers. IEEE Trans Energy Convers 26(1):195-203

20. Ibrahim AO, Nguyen TH, Lee DC, Kim SC (2011) A fault ridethrough technique of DFIG wind turbine systems using dynamic voltage restorers. IEEE Trans Energy Convers 26(3):871-882

21. Amalorpavaraj R, Kaliannan P, Padmanaban S, Subramaniam U, Ramachandaramurthy VK (2017) Improved fault ride through capability in dfig based wind turbines using dynamic voltage restorer with combined feed-forward and feed-back control. IEEE Access 5:20494-20503

22. Abdusalam M, Poure P, Karimia S, Saadate S (2009) New digital reference current generation for shunt active power filter under distorted voltage conditions. Electr Power Syst Res 79:759-76

23. Ghamri A, Benchouia MT, Golea A (2012) Sliding-mode control based three-phase shunt active power filter: simulation and experimentation. Electr Power Compon Syst 40(4):383-398

24. Biricik S, Ozerdem OC, Redif S, Khadem SK, Basu M (2014) Real-time control of shunt active power filter under distorted grid voltage and unbalanced load condition using self tuning filter. IET Power Electron 7(7):1895-1905

25. Biricik S, Ozerdem OC, Redif S, Kmail MOI (2012) Novel hybrid active power filter structure to compensate harmonic currents and 
reactive power. In: IEEE mediterranean electro-technical conference (MELECON). pp 25-28

26. Biricik S (2013) A novel hybrid active power filter topology for harmonic current suppression and reactive power compensation. $\mathrm{PhD}$ Thesis, Near East University, North Cyprus

27. Ebadian M, Talebi M, Ghanizadeh R (2014) A new control method for improving the performance of UPQC under unbalanced and distortional load conditions. In: International power conference (PCS)

28. Biricik S, Komurcugil H (2016) Optimized sliding mode control to maximize existence region for single-phase dynamic voltage restorers. IEEE Trans Ind Inform 12(4):1486-1497
29. Biricik B, Khadem SK, Redif S, M Basu (2014) Control of the dynamic voltage restorer to improve voltage quality. In: IEEE international symposium on power electronics distributed generation systems (PEDG). pp 1-5

30. Khadem SK (2013) Power quality improvement of distributed generation integrated network using unified power quality conditioner. $\mathrm{PhD}$ Thesis, Dublin Institute of Technology 